\title{
MIRANDO DESDE NINGÚN LUGAR. UNA BREVE INTRODUCCIÓN A LA FILOSOFÍA DE THOMAS NAGEL*
}

\section{Premisa}

homas Nagel enseña «Philosophy and Law» en la Universidad de New York y es conocido como uno de los más brillantes filósofos morales de Estados Unidos. Recordemos sus dos bellos libros, Mortal Questions (1979) y The View from Nowhere (1988). En su libro más reciente, What Does It All Mean? A Very Short Introduction to Philosophy (1987), el estudioso americano afronta de forma ágil algunas de las más importantes cuestiones tradicionalmente objeto de la reflexión filosófica y ofrece al lector un aprovechable compendio de su pensamiento. En las páginas que siguen intento recorrer las tesis principales desarrolladas por Nagel en este último libro haciendo referencia también a los argumentos e ideas de su obra precedente. Espero así poder ofrecer un cuadro bastante completo, en tanto que sintético, de la elaboración teórica de este autor, con particular atención a sus tesis éticas y metaéticas.

\section{Conocimiento y mente}

En What Does It All Mean? la primera pregunta que Nagel se plantea es: ¿cómo conocemos? Se atribuye así, en cierto sentido, a la teoría del conocimiento la responsabilidad de suministrar el esqueleto del cuerpo de la reflexión filosófica.

* «Desafortunadamente, para la redacción de este trabajo no he podido tomar en cuenta el último libro de Thomas Nagel que acaba de ser publicado por Oxford University Press: Equality and Partiality. Sin embargo, este libro no modifica las teorías éticas y metaéticas del estudioso norteamericano; más bien desarrolla la vertiente filosófico-política de su pensamiento». 
El estudioso americano afronta en primer lugar la hipótesis según la cual, a fin de cuentas, la única realidad existente es el yo. En efecto, ¿cómo puedo, saber que lo que yo concibo como existente existe verdaderamente y no es sólo una ilusión de los sentidos, un profundo sueño sin fin? Para superar este impasse podría sostener que ya que mis sentidos registran algo, son estimulados por algo, debe existir un algo que pueda ser registrado por, o que pueda estimular, mis sentidos. Esto no es, sin embargo, más que un argumento circular: para probar la fiabilidad de mis sensaciones apelo a su fiabilidad. O bien debería dar por supuesto la realidad de un mundo externo a mi yo, la cual sigue sin poder ser afirmada sobre la base de mis únicas sensaciones. El problema de la existencia de una realidad externa se proyectaría después en el problema relativo a las llamadas "other minds»: ¿existen otros seres más allá de mí?

La conclusión solipsista -señala Nagel- es desalentadora, y también injustificada. ¿Cómo puedo, partiendo de mis sensaciones, excluir que exista un mundo externo a las sensaciones mismas? Una conclusión más aceptable que la de la tesis solipsista sería entonces la de suspender el juicio sobre la realidad ${ }^{1}$, y asumir una posición escéptica moderada.

Podría tal vez rebatirse la posición del escéptico extremo con una observación de Wingenstein que reconoce la posibilidad y el sentido de la duda en un determinado juego lingüístico. «La pregunta del idealista -escribe el filósofo vienés- podría ser ésta: «¿Con qué derecho no dudo de la existencia de mis manos? (Y la respuesta no puede ser: "sé que existen»). Pero quien plantea esta pregunta olvida el hecho de que la duda acerca de una existencia funciona sólo en un juego lingüístico. Y que, por tanto, primero se debería preguntar: ¿qué aspecto tendría una duda así? Y esto no se comprende fácilmente»².

Esta observación de Wittgenstein repropone, aunque en términos superados respecto al primer neopositivismo lógico, el vínculo indisoluble entre condiciones de verdad o veracidad y condiciones de significado. Mientras que para Schlick, Carnap y el «primer» Wingenstein tiene sentido, es significativo, sólo lo que puede ser verdadero o falso, parece que para el «último»

${ }^{1}$ Esta es, por ejemplo, la recomendación del señor Montaigne. Vid. M. de Montaigne, Essais, livre 1, chapitre 27 ed. Flamarion, vol. 1. París 1969, p. 228. [Hay trad. cast. de C. Romá y Salmero, Ensayos, París, Garnier Hermanos 1912. N. del T.].

${ }^{2}$ L. Wittgenstein: Über Gewissheit, in ID., Werkansgabe, Bd \&, Suhrkamp, Frankfurt am Main 1990, p. 124. Traducción del propio autor. [Hay trad. cast., Sobre la certidumbre, Buenos Aires, ed. Tiempo Nuevo 1972. N. del T.]. 
Wittgenstein lo que es verdadero puede serlo sólo en la medida en que tiene sentido para una cierta comunidad lingüística. A esta concepción se puede replicar -como hace Nagel- que el lenguaje humano, sea cual sea la comunidad de la cual es expresión, «nos permite sobrepasar las respuestas para hablar del mundo mismo» ${ }^{3}$. Existen en cada lenguaje natural conceptos que transcienden la comunidad de la cual ese lenguaje es expresión y reenvían a la idea de objetividad, sobre la cual se funda el habla reflexiva sobre el mundo. El lenguaje natural no es un sistema autoreferencial, sino una estructura simbólica para dar cuenta y razón de algo que es externo a ella. «El lenguaje -como escribe Nagel- va más allá de sí mismo, tanto en el concepto de lluvia como en el concepto de lo que es, también si aquello que abarca puede ser indicado sólo usando el lenguaje o cualquier otra forma de representación» ${ }^{4}$.

En What Does It All Mean? la solución -si así se puede llamar- propuesta por el filósofo americano está instalada sobre un argumento de carácter pragmático. No obstante las dudas del escéptico, nosotros continuamos viviendo como si la realidad externa al yo existiese verdaderamente.

Nagel recurre aquí a una especie de intuicionismo gnoseológico, el cual, sin embargo, como todos los intuicionismos tiene el grave defecto de no afrontar el problema de la justificación de ciertas convicciones o creencias (intuitivamente dadas por buenas). «Si una creencia en el mundo externo a nuestras mentes -escribe- nos viene de una forma tan natural, tal vez no tengamos necesidad de razones para ella. Podemos simplemente dejar que exista y que sea justa» ${ }^{5}$.

En The View from Nowhere, su obra más sistemática y amplia, Nagel distingue tres tipos de teorías del conocimiento: (i) «escépticas», (ii) «reductivas», (iii) «heroicas». Son teorías «escépticas» aquellas que creen que el contenido de nuestras creencias sobre el mundo va más allá de la justificación producida por ellas. Se llaman teorías «reductivas» aquellas para las cuales nuestras creencias no versan sobre la realidad como ella es efectivamente, sino sólo sobre la realidad tal como se nos muestra» ${ }^{6}$. Se llaman

${ }^{3}$ Th. Nagel: The Viewfrom Nowhere. Cit. por trad. it. de A. Besussi Uno sguardo da nessun luogo, ed. de S. Veca Il Saggiatore, Milano 1988, p. 133.

${ }^{4}$ Ibidem.

${ }^{5}$ Th. Nagel: What Does It All Mean? A Very Short Introduction to Philosophy. Cit. por trad. it. de A. Besussi Una brevissima introduzione alla filosofia, a cura di S. Veca, Il Saggiatore, Milano 1989, p. 22. de Walt Whitman:

${ }^{6}$ Una bella formulación de lo que Nagel llama «reduccionismo» se encuentra en los siguientes versos 
teorías «heroicas, en fin, aquellas que reconocen la existencia de una discrepancia entre los contenidos de nuestras creencias sobre el mundo, de un lado, y las razones adoptadas para justificar esas creencias de, otro; y, por consiguiente, buscan colmar esta divergencia mediante formas varias de metafísica».

«Escepticismo»y «heroísmo» representarían para Nagel posiciones «realistas». El «reduccionismo» constituiría sin embargo una posición «idealista». «Realismo» significa «el punto de vista según el cual el mundo es independiente de nuestra mente» ${ }^{7}$. «Idealismo» es, en cambio, el punto de vista según el cual «lo que es es lo que podemos pensar o concebir, o aquello que nosotros o nuestros descendientes podremos estar en condiciones de pensar o concebir» ${ }^{8}$.

Nagel defiende una forma de teoría del conocimiento que es al mismo tiempo «realista»y «antiempirista». Es «realista», en cuanto sostiene que la realidad existe, prescindiendo de nuestras posibles sensaciones y representaciones de ella. «Lo que existe -escribe-, o aquello que es real no coincide necesariamente con aquello que para nosotros es un posible objeto del pensamiento»?.

Nagel es, con todo eso, «antiempirista», o «racionalista», como él mismo se define, en cuanto sostiene que «también el conocimiento empírico, debe fundarse sobre una base a priori ${ }^{10}$. Esta base a priori vendría proporcionada por una capacidad innata a los seres humanos, no necesariamente basada sobre la experiencia, de elaborar hipótesis sobre cómo puede ser en general la realidad. Se postula, así, la presencia de un vínculo tal entre nosotros y el mundo que resulte que nosotros estemos en situación de comprender algunos comportamiento del mundo. La inducción, por ejemplo, es explicada por Nagel en referencia a esta compatibilidad entre los hombres y el mundo como «necesaria para que el pensamiento produzca conocimiento» ${ }^{11}$.

Sin embargo, la impostación «realista» y «racionalista» de Nagel está lejos de teñirse con tonos escépticos. La búsqueda de

«May-be the things I perceive, the animals, plants, mean, hills, shining and flowing waters, the skies of day and night, colors, densities, forms, may-be these are (as doubtless they are) only apparitions, and the real sornething has yet to be known (W. Whitman: Leaves of Grass, The 1892, with an Introduction by J. Kaplan, Bantam, London 1983, p. 98).

${ }^{7}$ Th. Nagel: The View from Nowhere. Cit. por la trad. it. Uno sguardo da nessun luogo, p. 111

${ }^{8}$ Ibidem.

${ }^{9}$ Ibid., p. 115.

${ }^{10}$ Ibid., p.103.

${ }^{11}$ Ibid., p. 104. 
la objetividad del conocimiento, que también va seguida de decisiones, está expuesta al menos -según el filósofo americano- a tres peligros. (a) El primero es el peligro de una excesiva impersonalidad. Si se busca la máxima objetividad en la actitud respecto al mundo, se corre el riesgo de minusvalorar la importancia del yo. El yo es, sin embargo, condición de la perspectiva objetiva. El acceso al mundo nos viene dado por las sensaciones, las cuales son eminentemente subjetivas. Y sólo a partir de éstas es posible la perspectiva objetiva. La conclusión es entonces la siguiente: «Debemos predisponernos de algún modo a ver el mundo o bien desde ninguna parte, o bien desde aquí» ${ }^{12}$.

(b) El segundo riesgo es el de la «falsa objetivación». El tipo de objetivación del conocimiento depende también del objeto de éste. Existen ámbitos donde no es válido (o aplicable) un cierto tipo de objetivación, que en cambio puede ser válido (o aplicable) en otros ámbitos del conocimiento. «La incapacidad de reconocer los límites -afirma Nagelproduce varios tipos de obstinación objetiva, y sobre todo relevantemente análisis reductivos de un tipo de objeto, en términos que son tomados de la comprensión objetiva de otro» ${ }^{13}$.

(c) El tercer riesgo es, en fin, el del conflicto entre el punto de vista «objetivo» y el punto de vista «subjetivo». Sobre todo, por lo que respecta a la comprensión de nosotros mismos, es necesario hacer que la perspectiva objetiva comprenda de alguna manera, o sea compatible, con la perspectiva subjetiva, es decir, con la imagen que nosotros tenemos de nosotros mismos. Lo que se necesita es, por tanto, una «visión doble»: de un lado debemos considerar el mundo como regido por leyes naturales extrañas a cada una de nuestras intervenciones, pero por otro lado no podemos sustraernos a la duda de que «nuestras creencias derivan de ciertas inclinaciones y experiencias que, por lo que sabemos, no garantizan su verdad y son compatibles con el error radical» ${ }^{14}$.

Un problema al que Nagel dedica constante atención, conectado también a la temática gnoseológica, es el de las relaciones entre mente y cuerpo. Este problema puede ser reformulado del siguiendo modo: ¿es la mente algo distinto del cerebro considerado como un órgano del cuerpo humano que es una masa física o se identifica completamente la mente con el cerebro? O bien: ¿son los procesos mentales algo distinto a los procesos físicos o químicos que corresponden a éstos en la masa cerebral, o
${ }^{12}$ Ibid., p. 107.
${ }^{13}$ Ibidem.
${ }^{14}$ Ibid., p. 108. 
coinciden del todo con tales procesos físicos o químicos? Es evidente que estas cuestiones tienen un impacto considerable respecto, también, a la teoría del conocimiento.

Una respuesta tradicional al problema de la relación entre mente y cuerpo es el del «alma», es decir la tesis por la cual el ser humano está hecho de dos cosas fuertemente heterogéneas: una entidad corporal y una entidad espiritual, la cual es tan autónoma de la otra como para sobrevivirla. Si se refuta esta hipótesis normalmente nos encontramos delante de dos concepciones alternativas. (i) La primera concepción, que Nagel llama «físicalismo» o «materialismo», afirma que las personas están hechas sólo de materia física, y que los estados mentales, sentimientos, deseos, placeres, dolores, no son otra cosa que estados físicos del cerebro, en vía de principio, comprobables por un observador externo ${ }^{15}$.

(ii) Una segunda teoría, llamada del «doble sentido», sostiene, al contrario, que los estados mentales, siendo procesos internos al cerebro, son internos a éste en un modo que es imposible experimentar si no hay alguien que los vive. Esto significa que, por ejemplo, un dolor, o un placer, aunque tengan un correspondiente estado físico en la masa cerebral, no son reducibles a ese estado físico en la masa cerebral, no son reducibles a ese estado físico. Dolor y placer -según esta perspectiva- poseen una internalidad accesible, experimental, «observable» sólo por el sujeto mismo del dolor o del placer ${ }^{16}$. Esto tiene como consecuencia que los estados mentales, como el dolor o el placer, no puedan ser explicados exclusivamente en relación con las causas que los provocan.

Nagel se adhiere a la teoría llamada del «doble aspecto». «Es verdad-escribe- que los dolores son causados por una lesión, y te hacen gritar y cojear. Pero también se sienten de cierta manera, y esto parece ser algo diverso a todas las relaciones causa-efecto, como a todas las propiedades físicas que pueda haber -si son de hecho eventos en tu cerebro. Por lo que a mí respecta, creo que este aspecto interno del dolor y de otras

${ }^{15}$ Una posición de este tipo puede atribuirse, por ejemplo a Gilhert Ryle. Vid., por ejemplo, The Concept of Mind, Penguin, Harmonds Worth 1983, pp. 51-60, y cfr. A.J. Ayer: Philosophy in the Twentieth Century, Unwin, London 1987, p. 164 ss.

${ }^{16}$ Sostiene esta tesis, por ejemplo, Cornelius Castoriadis: «On ne peut pas par le pensée reconstituer la douleur specifique de celui qui vient de subir telle operation ou de pedre telle personne aimée». (C. Castoriadis: L'état du sujet aujord'hui, en ID., Le monde morcelé, Seuil, París, 1990, p. 199). 
experiencias conscientes no puede ser adecuadamente analizado en los términos de un sistema de relaciones causales con estímulos físicos y comportamientos, por complejo» ${ }^{17}$. La conclusión de este razonamiento es, entonces, que existen muchas más cosas en el mundo de cuantas pueden ser explicadas por las ciencias empíricas.

La tesis gnoseológica de Nagel es, sin embargo, todavía más radical. Movida por la constatación de que lo que es subjetivo no es comprensible ni explicable sino desde el punto de vista del sujeto en cuestión ${ }^{18}$, que nuestra imaginación está determinada por nuestra experiencia, y ésta a su vez depende de nuestra estructura sensorial, Nagel añade la conclusión que pueden existir hechos para cuya observación o comprensión no disponemos de instrumentos adecuados.

Así como nosotros no estamos en situación de entender qué «efecto produce»ser un murciélago, de igual forma un eventual extraterrestre, provisto de una estructura físico-psíquica distinta de la humana, no podría comprender el «efecto que produce» ser un hombre. «Mi realismo -escribe el estudioso- a propósito del dominio subjetivo en todas sus formas, implica una creencia en la existencia de hechos que exceden los conceptos humanos. Es ciertamente posible para un ser humano creer que existen hechos a propósito de los cuales los humanos no poseerán jamás los conceptos necesarios para representarlos o comprenderlos» ${ }^{19}$. «Una reflexión sobre qué efecto produce ser un murciélago -continúa Nagel- nos lleva a la conclusión de que existen hechos que no consisten en la verdad de las proposiciones expresables en un lenguaje humano. Podemos estar constritos a

${ }^{17}$ Th. Nagel: What Does It All Mean? Cit. por trad. it., Una brevissima introduzione alla filosofia, p. 45, cursiva en el texto. Conclusiones similares extrae Rodolfo De Stefano catedrático de Filosofia del Derecho en la Universidad de Messina fallecido hace dos años: «Al materialista o conductista moderno se le puede conceder tal vez, y con las oportunas reservas, que algún elemento material y sensible pueda encontrarse en la más profunda interioridad de la consciencia. Pero este elemento no agota cada contenido de la vida humana consciente. Siendo la materia una realidad demasiado determinada y específica, mientras que la consciencia transciende en cada uno de sus contenidos no sólo a la realidad material sino, además, toda realidad» (R. de Stefano, Fantasia e realtà, en Scritti catanzaresi in onore di Angelo Falzea, Edizioni scientifiche italiane, Napoli 1987, p. 91).

${ }^{18}$ Nagel comparte por ello la siguiente afirmación de Castoriadis: «On ne peut penser le vivant que de l'interieur» (C. Castoruadis, op. ult. cit., p. 200).

${ }^{19}$ Th. Nagel: Mortal Questions Cit. por trad. it. de A. Bessuni, Questioni mortali, a cura di S. Veca, Il Saggiatore, Milano 1986, p. 167. Cursiva en el texto. 
reconocer la existencia de hechos de esa clase sin estar en condiciones de explicarlos o comprenderlos» ${ }^{20}$.

Nagel, siendo contrario a cada tipo de reducción fisicalista o positivista del mundo, es en cambio fuertemente crítico con la visión antropocéntrica de la realidad. El mundo, en su opinión, existe prescindiendo de nosotros y de lo que nosotros percibimos o sabemos. Su acentuación del rol de la mente no desemboca en posiciones idealistas, ni tampoco en una teoría del alma que presuponga el soplo divino, como sucede con John Eccles. La mente es concebida -según Nagel- (a) como una parte del mundo externo, y (b) como un atributo no necesariamente exclusivo de los seres humanos. "Aún si las características subjetivas de nuestras mentes están en el centro de nuestro mundo, debemos intentar concebirlas sólo como manifestaciones de la mente en un mundo que no está hecho a la medida del hombre» ${ }^{21}$.

\section{Lenguaje y acción}

Thomas Nagel se mide también con un tema que ha sido cara y cruz de generaciones de filósofos analíticos, entre los cuales él mismo puede contarse: ¿cuál es el significado de las palabras y las expresiones lingüísticas? Para los estudiosos neopositivistas -como es sabido- ésta ha sido una cuestión filosófica de particular relieve, previa a muchas otras.

Nagel no comparte la idea de la centralidad de la reflexión sobre el significado, convencido de que los mayores problemas filosóficos no derivan principalmente de un mal uso del lenguaje. No obstante, reserva un lugar importante a la teoría del significado, en particular en What Does It All Mean? Su posición puede calificarse en wittgensteiniana, en el sentido de que se adhiere -aunque con prudencia- a la concepción del significado como «uso».

Nagel es particularmente crítico frente a la teoría que se suele llamar «referencial» ${ }^{22}$, es decir frente a la teoría que sostiene que el significado de un término viene dado por los objetos existentes en el mundo que son denotados por él. El estudioso americano advierte contra el riesgo, contenido en las teorías referenciales, de

\section{${ }^{20}$ Ibid., p. 168.}

${ }^{21}$ Th. Nagel: The View from Nowhere. Cit. por trad. it. p. 21. p. 12 ss.

\footnotetext{
${ }^{22}$ Cfr. W.P. Alston: Philosophy of Language, Prentice-Hall, Englewood Cliffs, N.J. 1964,
} 
cambiar los términos por nombres propios como «Juan», «Pedro», «Madrid», etc. El significado de un término tiene, en su opinión, una universidad que no se deja encerrar en ningún objeto particular. "Todos nosotros -escribe- hemos visto y olido el tabaco, pero la palabra, en el modo en que se usa, se refiere no sólo a las muestras de material que has visto, o que se encuentran en tu entorno cuando usas la palabra, sino a todos los ejemplares de éste, sepas o no de su existencia. Puedes haber aprendido esa palabra, porque te han enseñado muestras, pero no la comprenderás si piensas que es sólo el nombre de esas muestras $»^{23}$.

El significado de un término o de un enunciado no puede obtenerse del uso individual de éstos como tampoco el sentido de una regla puede recabarse de la singular aplicación de ésta.

Palabras y enunciados pueden ser empleados, reglas y normas pueden ser observadas y aplicadas, en una infinidad de modos y en una infinidad de casos, sin que el modo y el caso singular agote nunca el significado de las palabras, enunciados, reglas, normas. Sobre esto reclama nuestra atención entre otros Jürgen Habermas. "El significado de las palabras y enunciados -escribe haciendo referencia explícita al "segundo" Wittgenstein - tiene [...] respecto a cada particular uso un excedente de universalidad $\rangle^{24}$.

Nagel es crítico también con la denominada teoría "mentalista», según la cual el significado de un término es la idea o imagen que ese término evoca en nuestra consciencia. También aquí la crítica se apoya sobre la afirmación de la universalidad típica del significado de una expresión lingüística, tal que dos personas que nunca se hubieran visto antes están en grado de entenderse, o tal que yo hoy puedo entender una poesía de Catulo, frente a la particularidad de la imagen mental. «Aunque, si tienes en la mente una imagen - escribe el estudioso americano- cuando oyes o usas la palabra "tabaco", cualquier otra persona tendrá una imagen diferente; esto sin embargo no nos impide usar la palabra con el mismo significado» ${ }^{25}$.

Nagel es del mismo modo crítico (i) de la teoría conductística del significado y (ii) de la tesis del denominado «private language», es decir (i) de la teoría para la cual el significado de las expresiones lingüísticas es reducible a una determinada relación estímulo / respuesta para emisor y receptor, y (ii) de la tesis para la

${ }^{23}$ Th. Nagel: What Does It All Mean? Cit. por trad. it., p. 50.

${ }^{24}$ J. Habermas: Wahrheitstheorien ahora en ID., Vorstudien und Ergänzungen zur Theorie des kommunikativen Handelns, Suhrkamp, Frankurt am Main 1984, p. 156. Traducción del propio autor.

${ }^{25}$ Th, Nagel, op. ult. cit., pp. 53-54. 
cual es posible, en línea de principio, construir un lenguaje completamente independiente de cada relación intersubjetiva. A la tesis conductista Nagel no puede ser reconducido enteramente a su elemento pragmático, o sea, a la relación específica existente entre un determinado emisor y un determinado destinatario de la expresión. "Una aserción como "La sal está sobre la mesa" significa la misma cosa, dicha con fines prácticos durante una comida, como parte de la descripción de una situación distante en el espacio y en el tiempo, o simplemente como descripción hipotética de una posibilidad imaginaria. Significa lo mismo, sea verdadera o falsa, y que el hablante y el oyente sepan o no aun que es verdadera o falsa» ${ }^{26}$.

A la tesis del «private language» Nagel objeta que el uso que fundamenta el significado de la expresión lingüística es sólo el social. «Mi uso de la palabra "tabaco" no tiene un significado por sí mismo, antes bien como parte del uso mucho más amplio de esa palabra en el idioma concreto. (Aunque si yo hubiese adoptado un código privado en el cual he usado la palabra "babla", para decir tabaco, lo habré hecho definiendo "babla" para mí mismo en los términos de la común palabra "tabaco")»» ${ }^{27}$. Nagel, pues, no niega que el «lenguaje privado» sea posible: niega que sea autosuficiente. La semántica de un lenguaje exclusivamente personal reenvía a la semántica de un cierto lenguaje natural (socialmente instituido), y es parasitaria respecto a esta última.

El uso constitutivo del significado de un término no es el uso efectivo que de él hace un cierto sujeto, sino el uso posible en el cuadro de un cuerpo regular de reglas sedimentadas en una costumbre social (yo me atrevería a decir en una «institución» ${ }^{28}$ ). «El significado de una palabra - escribe Nagel- contiene todos sus usos posibles, verdaderos o falsos, no sólo sus usos efectivos, los usos efectivos son sólo una fracción mínima de los posibles» ${ }^{29}$.

Aceptada la teoría del significado como «uso», difícilmente puede sustraerse a una consideración de la conducta humana. La teoría del «uso» reenvía a una teoría de la acción ya que el uso lingüístico no es otro que una particular forma de comportamiento humano. Nagel no evita esta implicación; al contrario le dedica

${ }^{26}$ Ibid., p. 55. La traducción italiana de A. Bessuni es aquí levemente modificada por el propio autor.

${ }^{27}$ Ibid., p. 56.

${ }^{28} \mathrm{Cfr}$. M. La Torre: Linguaggio, norme, validità. Una prospettiva istituzionalistica, in N. Maccormick, O. Weinberger, Il diritto come istituzione, trad. it. a cura di M. La Torre, Giuffrè, Milano 1990, p. 382 ss.

${ }^{29}$ Th. Nagel, op. ult. cit., p. 56. 
mucha atención a la teoría de la acción. Ésta - como es sabido- gira entorno a un problema fundamental, el llamado «libre arbitrio». A este propósito el estudioso americano se enfrenta a la llamada concepción «determinista».

El determinismo en cuestión es aquel para el cual las acciones de los seres humanos están determinadas por causas externas a esas acciones. Aquí «la hipótesis es que existen leyes de naturaleza, como las que gobiernan el movimiento de los planetas, que gobiernan todo lo que sucede en el mundo -y que, de conformidad a esas leyes las circunstancias precedentes a una acción determinan lo que sucederá y excluyen cualquier otra posibilidad $»^{30}$. Así pues, si hoy en la comida me encontré con la alternativa de elegir entre un dulce de mascarpone o una naranja, y -cediendo a la tentación y olvidando cualquier problema de hígado o de línea- he optado por el dulce de mascarpone, y estoy aquí ahora mortificándome por mi elección, agobiado por el sentimiento de culpabilidad, todo esto había estado ya predeterminado: que mi padre y mi madre se encontraran, tuvieran un hijo varón, que este se licenciara en Derecho, y se encontrase un día de mayo en un self-service de Bologna, y que finalmente eligiese justamente el dulce de mascarpone. «Si el determinismo - escribe Nagel- vale para todo lo que sucede, estaba ya establecido antes de que tú nacieses que habrías elegido el dulce. Tu elección estaba determinada por las situaciones inmediatamente precedentes y esa situación estaba determinada por las situaciones que la precedían, y así hacia atrás hasta donde quieras llegar» ${ }^{31}$.

La objeción que Nagel opone a este determinado es principalmente de carácter metaético. Si es verdad -argumenta al estudioso americano- que nuestras acciones son predeterminadas por elementos externos a ellas, entonces es imposible expresar un juicio moral (sea de elogio sea de censura) sobre la conducta de las personas. Si no se es responsable de las propias acciones, como acaba por sostener ese «determinismo», ¿cómo se puede valorar las acciones, según un criterio moral o normativo? «Por lo que a mí respecta -escribe Nagel-, no pienso que tenga sentido criticar a alguien por hacer lo que era imposible para él no hacer» ${ }^{32}$. La asunción de juicios morales, los cuales implican atribuciones de responsabilidad, resulta incompatible con una visión radicalmente «externa» del mundo como es el determinismo

\footnotetext{
${ }^{30}$ Ibid., p. 63. Cursiva en el texto.

${ }^{31}$ Ibid., pp. 63-64. Cursiva en el texto.

${ }^{32}$ Ibid., p. 66.
} 
naturalista, ya que éste excluye el concepto de responsabilidad subjetiva. «No consigo ver - escribe el estudioso americano- ningún modo de producir juicios de responsabilidad coherentes con la visión externa -ningún modo de vincularla con tales juicios del mismo modo que se la suele vincular parcialmente con la acción. Los juicios de responsabilidad dependen de una clase de proyección en la perspectiva del imputado, que no podemos realizar al menos que olvidemos en cierta medida la visión externa» ${ }^{33}$.

A esta objeción se podría añadir aquella que advierte cómo, si se asume una hipótesis determinista fuerte, resulta entonces posible, en vía de principio, conocer los valores morales (los valores de un sujeto determinado), ya que también estos son el producto de ciertas causas según ciertas leyes. Si todo está predeterminado, también las decisiones individuales y los valores en los cuales dichas decisiones dicen inspirarse, o son también ellos elementos de la cadena causal, o bien ilusiones o autoilusiones ideológicas. Queda en cualquier caso el hecho de que los valores, sea lo que sea lo que representen, son «predeterminados» y por tanto predecibles es decir verificables y cognoscibles. Un determinismo riguroso se revela por tanto incompatible con una opción no cognoscitivista. Si se asume una posición determinista fuerte, entonces se da por entendido que el precio a pagar es el abandono de toda metaética no cognoscitiva.

Nagel, sin embargo, no reniega de todas las formas de determinismo. En su opinión, pensar que la acción humana sea del todo indeterminada comporta igualmente consecuencias inaceptables desde el punto de vista metaético: también una acción privada absolutamente de causas no sería imputable al sujeto que la realiza, de manera que este no podría ser considerado moralmente responsable de aquella acción. El estudioso americano acoge esa forma moderada de determinismo la cual considera que las causas de una acción son internas a ésta, o bien que tales residen en las elecciones del agente. «La tesis es que, para que una acción sea algo que has hecho, debe estar producida por ciertos tipos de causas en ti» ${ }^{34}$. «Según esta posición - continúa -la determinación causal en sí misma no amenaza la libertadporque solo un cierto tipo de causa lo hace. Si tomases el dulce porque alguien te ha empujado, entonces no sería una libre elección. Pero la acción libre no exige

${ }^{33}$ Th. Nagel: The View from Nowhere. Cit. por trad. it., p. 170.

${ }^{34}$ Th. Nagel: What Does It All Mean? Cit. por trad. it., p. 68. 
que no exista de ningún modo alguna causa determinante: implica que la causa sea de un tipo psicológico habitual» ${ }^{35}$.

\section{Valores y justicia}

El problema de la moral, de lo justo y de lo injusto, es central en la obra de Nagel. Pues es, en efecto y sobretodo, un estudioso de filosofía práctica y especialmente de filosofía moral.

En línea de principio Nagel critica las doctrinas que remontan el criterio de lo justo a la voluntad divina. A estas opone tres objeciones. (i) La mayoría de las personas que no creen en Dios expresan no obstante juicios de valor, valoraciones sobre lo que es justo o errado, y no consideran en absoluto que «todo está permitido». No es verdad, en efecto que «para un ateo, ni la palabra dada, ni los pactos, ni los juramentos, que son los vínculos de la sociedad humana, puedan ser estables o sagrados $\rangle^{36}$. Esto significa que se puede asumir un punto de vista moral, aun sin tener que presumir necesariamente la existencia de una entidad divina.

(ii) Aun si Dios existe y prohíbe lo que es injusto, a pesar de ello el criterio de lo justo no depende necesariamente de la interdicción divina. «Dios -escribe Nagel- no podría convertir en justa cualquier cosa que antes era errada simplemente prohibiéndola $»^{37}$.

(iii) Tanto el amor como la punición divina o bien, por lo que nos concierne como seres humanos, el miedo del castigo eterno o la esperanza de la recompensa celeste, no parecen ser los fundamentos más apropiados desde el punto de vista moral. «Si piensas que es errado matar, engañar o robar -continúa Nagel-, deberías querer evitar hacer cosas del género porque son cosas malas para las víctimas, y no sólo porque temes las consecuencias para ti mismo o porque no quieres ofender a tu creador» ${ }^{38}$. Esta última objeción se aplica también a todas las

${ }^{35}$ Ivi, p. 69, cursiva en el texto. Cfr. entre otros G. H. von Wright: An Essay on Door-Knocking, in «Rechtstheorie», Bd. 19, 1988, p, 287: «If we call action free when performed for a reason, there can be no conflict between «freedom» and «determinism» (cursiva en el texto), e o. Weinberger, Norm und Institution. Eine Einführung in die Theorie des Rechts, Manz, Wien 1988, p. 20 ss.

${ }^{36}$ J. Locke: A Letter Concerning Toleration. Cit. por trad. it. Prima lettera sulla tolleranza, vol. I, en ID., Scritti sulla tolleranza, trad. it. a cura di D. Marconi, U.T.E.T., Torino 1977, p. 172. [Hay trad. cast.: Carta sobre la Tolerancia, Madrid, Tecnos 1985. N. del T.].

37 Th. Nagel, op. ult. cit., p. 76.

${ }^{38}$ Ibid., p. 77. La traducción italiana de A. Besussi es aquí levemente modificada por el propio autor. 
doctrinas que explican la moral en términos de intereses egoístas del sujeto agente, y por tanto reconducen la reflexión moral a una clase de cálculo prudencial o utilitario.

Nagel es un crítico también respecto a la teoría que afirma como moralmente justo lo que se cree así en un cierto ámbito o grupo social. Es siempre posible -según el estudioso americano- ejercer la crítica respecto a la moral socialmente dominante (históricamente vigente) pero si eso es posible, entonces se hace referencia «a algún criterio más objetivo, una idea de lo que es verdaderamente justo o errado, contrapuesta a aquello que piensa la mayor parte de la gente» ${ }^{39}$.

Por otra parte el filósofo americano no cree que «lo que gusta» o «lo que no gusta» puedan ofrecer los criterios decisivos de lo justo. Es verdad por lo demás, que cuando se realiza algo que se considera es la «cosa justa», nos sentimos a menudo mejor, y que cuando se realiza una acción moralmente justa. La «sensación» o el «sentimiento» no son el fundamento o el criterio de la moralidad del acto, sino una consecuencia.

Queda entonces por individuar el criterio de la moralidad. Thomas Nagel parece inclinarse, aunque con mucha cautela, hacia una teoría de la universalización. «El fundamento de la moralidad -escribe- es una creencia en que el beneficio y daño a personas particulares [...] está bien o mal no sólo desde su punto de vista, sino desde un punto de vista más general, que cualquier persona pensante puede comprender $\rangle^{40}$. Este punto de vista, que también podemos llamar «the moral point of view» recordando el título de un libro ahora ya «clásico» de Kurt Baier, es el de un sujeto que busca abstraerse de los propios deseos e intereses e intenta reunir, dentro de lo posible, objetividad o imparcialidad en lo que concierne a la consideración ética. "Yo creo -escribe Nagel- que la forma general de razonamiento moral consiste en meterse en la piel de los otros $\rangle^{41}$.

Esta concepción de la moral como tensión hacia la «objetividad» es expresada de modo bastante claro ya en el primer libro de Nagel The Possibility of Altruism, que es una reelaboración de su tesis doctoral en filosofía (dirigida por John Rawls) leída en Harvard en 1963. En la conclusión de este libro encontramos las siguientes afirmaciones: «He intentado mostrar que el altruismo y los motivos conexos a él no dependen de los gustos, sentimientos, o de elecciones últimas arbitrarias. Dependen en cambio del

\footnotetext{
${ }^{39}$ Ibid., p. 86.

${ }^{40}$ Ibid., pp. 80-81.

${ }^{41}$ Th. Nagel: Mortal Questions. Cit. por trad. it., p. 128.
} 
hecho de que nuestras razones para actuar están sujetas a las condiciones formales de objetividad, la cual a su vez depende de nuestra capacidad de ver por nosotros mismos ya desde un punto de vista personal ya desde un punto de vista impersonal, y de nuestra capacidad de extraer del razonamiento conclusiones prácticas desde ambos puntos de vista. Estos representan formas de pensamiento y de acción respecto a los cuales puede suceder que no esté en nuestro poder renunciar ${ }^{42}$.

Cuáles sean los procedimientos o los medios para llegar a este estado de «objetividad» (o imparcialidad) ${ }^{43}$, no queda precisado ulteriormente. Según Nagel, la universalidad de los juicios morales está estrechamente conectada a su imparcialidad, y toma así la forma de una clase de virtud que algunos seres humanos poseen y otros ignoran. «El argumento moral -escribe el estudioso americano- trata de hacer referencia a una capacidad de motivación imparcial que se supone presente en todos nosotros. Desafortunadamente puede ser profundamente subterránea y en ciertos casos puede incluso no estar presente en absoluto» ${ }^{44}$.

Parecería así que, aunque con cierta perplejidad, el estudioso americano prefiera la ética de la virtud frente a las éticas deontológicas. La posición metaética de Nagel no es muy clara. Su constante subrayar la necesidad de «objetividad» del juicio moral le conduce a menudo a sobrepasar los confines del cognoscitivismo. Habla alguna vez de «verdad ética», y define su teoría metaética como «realismo normativo»: "Normative realism is the view that propositions about what gives us reasons for action, can be true or false independently of how things appear to us, and that we can hope to discover the truth by transcending the appearances and subjecting them to critical assessment $\rangle^{45}$.

Por otra parte, sin embargo, no cree que las proposiciones morales puedan ser convertidas en verdaderas por el descubrimiento de ciertas propiedades inherentes a las cosas y a los hechos. «The picture I associate with normative realism is not that of an extra set of properties of things and events of human motivation which would improve the way we lead our lives, whether or not we will

${ }^{42}$ Th. Nagel: The Possibility of Altruism, II ed, Clarendon, Oxford 1975, p. 144. Traducción del propio autor.

${ }^{43}$ Cfr. R.M. Hare: Moral Thinkings. Its Levels, Method and Point, Clarendon, Oxford 1984, p. 211.

${ }^{44}$ Th. Nagel: What Does It All Mean? Cit. por trad. it., p. 88.

${ }^{45}$ Th. Nagel: The View from Nowhere, Oxford University Press, New York 1986, p. 139. Cfr. S.L. Darwall: How Nowhere Can You Get (and Do Ethics), in «Ethics», vol. 98, 1987, p. 137 ss. 
actually take them ${ }^{46}$. Aquí al menos Nagel parece rechazar la teoría del valor intrínseco ${ }^{47}$, bosquejando, más bien, una clase de metaética evolucionista que puede recordar ciertas insinuaciones de la obra de Habermas y Apel $^{48}$, las cuales sugieren la posibilidad de un «progreso» o mejor de una «evolución» moral.

Con todo ello, el cognostivismo moderado de Nagel no le induce a adoptar una posición absolutista. A pesar sus oscilaciones hacia una metaética objetivista, asume una posición relativista. Esto le viene dado en particular por su concepción de la «fragmentación del valor»: «Value has fundamentally different kinds of sources» ${ }^{49}$.

Nagel distingue diversas «Fuentes de valor» o bien «cinco tipos de valores fundamentales que dan lugar a conflictos basilares $\rangle^{50}$.

(i) Ante todo, están los valores que derivan de obligaciones específicas hacia otros sujetos o instituciones. Un ejemplo es el constituido por las obligaciones hacia un amigo, hacia los familiares, hacia la organización en la cual se desarrolla el propio trabajo. Tales obligaciones no son generales, pues sólo son vigentes en situaciones particulares.

(ii) En segundo lugar, están los valores que derivan de los derechos generales (de los cuales cada ciudadano resulta titular) a prestar cierta conducta o a no ser objeto de actos determinados. Los derechos fundamentales de libertad representan un caso paradigmático de tales valores. Estos derechos generales no tienen origen contractual, no dependen del hecho de que terceros estén obligados a ciertas conductas, sino que son connaturales al estatuto de la persona.

(iii) El tercer tipo de valor es la utilidad. «La utilidad -escribe Nagel-incluye todos los aspectos de beneficio y daño hacia todos los individuos (o todos los seres sensibles), no sólo hacia aquellos con los cuales el agente tiene una relación particular, o ha contraído un compromiso específico» ${ }^{51}$.

${ }^{46}$ Th. Nagel, op. ult. cit, pp. 139-140.

${ }^{47}$ Sobre este teoría cfr. las agudas observaciones de P. Koller: Von der Vergeblichkeit des Bemühens, die Ethik auf eine Vorstellung intrinsischer Werte zu gründen, in «Grazer Philosophiche Studien», Bd. 28, 1986, p. 275 ss.

48 Vid. por ejemplo J. Habermas: Moralbewusstsein und kommunikatives Handeln, Suhrkamp, Frankfurt am Main 1985, p. 127 ss. y K.O. Apel: Diskurs und Verantwortung. Das Problem des Übergangs zur postkonventionellen Moral, Suhrkamp, Frankfurt am Main 1990, p. 306 ss.

${ }^{49}$ Th. Nagel: Mortal Questions, Cambridge University Press, Cambridge 1979, p. 132.

${ }^{50}$ Th. Nagel: Mortal Questions. Cit. por trad. it., p. 127.

${ }^{51}$ Ibid, p. 128. 
(iv) El cuarto tipo de valor está representado por los «fines y valores perfeccionistas». A propósito de estos fines Nagel usa la locución «valor intrínseco». Serían algunas realizaciones o algunos resultados que constituyen un valor prescindiendo de los intereses que los individuos puedan encontrar en ellos. Un ejemplo mencionado por Nagel es el valor intrínseco del descubrimiento científico» ${ }^{52}$. El estudioso americano reconoce, sin embargo, que no existe acuerdo general sobre los fines que constituyen de por sí valores dignos de ser perseguidos. Sobre cuáles sean los valores intrínsecos reina, una gran incertidumbre.

(v) El último tipo de valor individuado por Nagel es aquel constitutivo del «compromiso» con los propios proyectos o empresas». Éste es, por decirlo así, un valor subsidiario, en cuanto «se añade a todas estas razones que pueden habernos conducido a ellos» ${ }^{53}$. Un ejemplo citado por el autor es la obligación de traducir del griego la Metafísica de Aristóteles. Este compromiso de la persona no se confunde, de ningún modo, con el mero interés personal. Como muestra bien el ejemplo de la traducción de la Metafísica, la obligación en cuestión puede entrar en conflicto con los intereses personales del sujeto (aquél por ejemplo de salir con los amigos o de ganar algo más de dinero escribiendo un informe jurídico).

Como resulta bastante claro, con esta clasificación Nagel intenta una conciliación de diversas teorías morales. Con su clasificación abraza el utilitarismo, la teoría del valor intrínseco, una ética de los derechos, una ética deontológica, y en fin una ética existencial. Nagel da un orden a los varios tipos de valor arriba mencionados según su urgencia, así que (i) resulta más urgente que (ii), (ii) más urgente, a su vez, que (iii), y (iv) que (v). Esto sin embargo no significa que (iii) no pueda prevalecer en algunas situaciones sobre (ii) o sobre (i), o que (v) sea mejor que (iv), y así en adelante. El orden de «urgencia» no nos da todavía un criterio de prioridad tal que resuelva los eventuales conflictos entre valores diferentes en cada situación.

Nagel realiza una ulterior graduación, dentro de las cinco categorías antedichas según se trate de valores más o menos impersonales, más o menos «objetivos», más o menos centrados sobre el agente (o bien sobre lo que se hace) o sobre el resultado

\footnotetext{
${ }^{52}$ Esto puede recordar lo afirmado por J. Finnis: Natural Law and Natural Rights, Clarendon, Oxford 1980, p. 62.

${ }^{53}$ Th. Nagel, op. ult. cit., p. 129.
} 
(o bien sobre lo que resultara) ${ }^{54}$. En un espectro que vaya de (i) a (v), (i) representa el valor más personal o menos centrado en el resultado, y (v) el valor más impersonal y menos centrado sobre el agente.

Para Nagel la moral no se compone sólo de valores «neutrales» respecto al agente; muy al contrario, la reducción de la razón «relativa respecto al agente» a razones «neutrales» se considera destinada a la quiebra. La decisión moral resulta así de la combinación de estos dos tipos de «razones», y no de la prevalencia en cada caso de las razones «neutrales» (o «objetivas») sobre las «relativas» (o «subjetivass»). La oposición entre razones objetivas e inclinaciones subjetivas -escribe el estudioso americano- puede ser grave, y puede requerir cambiar nuestra vida. Quiero decir sólo que la verdad, si es una, se conquistará a través de la exploración de este conflicto, más bien que a través de la automática victoria de la perspectiva más transcendente. En la conducta vital, en todas las situaciones, la rivalidad entre la visión interna y la visión externa debe ser tomada en serio» ${ }^{55}$.

El valor o razón «neutral respecto al agente» es por excelencia -según Nagel- la búsqueda del placer, o la huida del dolor. Placer y dolor son entendidos aquí como placer o dolor físico, y no se confunden con deseos o con las preferencias del sujeto. El estudioso americano plantea la siguiente cuestión: «¿Placer y dolor contienen solamente valor agente-relativo o suministran también razones neutrales? Si evitar un dolor tiene sólo valor relativo, entonces los individuos tienen razón para evitar su dolor, pero no para aliviar el dolor de otros (al menos que entren en juego otras razones). Su aliviar un dolor tiene también un valor neutral, entonces cualquiera tiene razón para querer que cualquier dolor cese, sea suyo o no» ${ }^{56}$. La respuesta que Nagel da a este dilema es que «el dolor, por cuanto está ligado a una persona y a su perspectiva individual, es igual y claramente odioso tanto para el sujeto objetivo como para el individuo subjetivo» ${ }^{57}$.

En The View from Nowhere Nagel propone una ulterior tipología de valores o razones para la acción. Tales razones son llamadas de «autonomía», de «deontología», y de «obligación», razones todas «relativas respecto al agente». Las primeras consisten en los deseos, proyectos, y compromisos personales del

\footnotetext{
${ }^{54}$ Sobre esta distinción vid. Th. Nagel: Mortal Questions, cit., capítulo sexto.

${ }^{55}$ Th. Nagel: The View from Nowhere. Cit. por trad. it. (parcialmente modificada), p. 202.

${ }^{56}$ Ibid., p. 196

${ }^{57}$ Ibid., p. 198.
} 
agente. Este tipo de razones coinciden grosso modo con aquellas que Nagel en Mortal Questions hace derivar del compromiso con los propios proyectos o empresas.

Las razones de «deontología» «derivan de las pretensiones de otras personas de no ser maltratadas de ciertas formas $»^{58}$. Estas razones coinciden grosso modo con esos valores que en la clasificación propuesta en Mortal Questions estaban en segundo lugar, es decir con los valores que se afirmaban derivaban de los derechos generales de los individuos a no ser sometidos a ciertos tratamientos.

En fin «razones de obligación» son aquellas que derivan de participar en ciertos contextos concretos (familia, instituciones varias, Estado) y corresponden al primer tipo de valores, aquellos derivados de las obligaciones específicas, de las cinco individuadas en Mortal Questions. Las razones de «autonomía», «deontología» y «obligación» no comprenden en cambio los «valores perfeccionistas» y los «valores de utilidad» mencionados por Nagel en su clasificación precedente, ya que tanto los «valores perfeccionistas» como aquellos de «utilidad» constituyen razones no «relativas», sino «neutrales» respecto al agente.

Para Tom Nagel no existe un único método para ajustar el eventual conflicto entre los varios tipos de valores o razones. «Buscar una teoría general única -escribe- para decidir lo que es justo hacer, es como buscar una singular teoría para decidir que es lo que hay que creer» ${ }^{59}$. Lo que se puede y se debe hacer es sobretodo desarrollar procedimientos de argumentación moral relativa a problemas específicos, y confiar en la sabiduría práctica, en la «prudencia», de los seres humanos.

Nagel recurre también a la intuición moral de los sujetos, interpretando la «prudencia» como juicio intuitivo no siempre necesariamente capaz de ofrecer razones articuladas por las propias decisiones. «Sostengo - escribe- que puede existir un buen juicio sin justificación total, explícita o implícita. El hecho que no se pueda decir por qué una cierta decisión es correcta, dado un particular equilibrio de razones conflictuales, no significa que la pretensión de corrección esté falta de significado» ${ }^{60}$.

${ }^{58}$ Ibid., p. 204.

${ }^{59}$ Th. Nagel: Mortal Questions. Cit. por trad. it., p. 134.

${ }^{60} \mathrm{Ibid}$., p. 133. Confieso que la llamada a la intuición, allí donde forma parte de un discurso no tanto sobre el proceso motivacional que conduce a la decisión, sino en cuanto se la hace entrar en el contexto de la justificación de la decisión, me deja perplejo y desconfiado. Análoga perplejidad, también, cfr. J. Glover, recensión de Th. Nagel, Mortal Questions, en «Mind», vol 90, 1981, p. 295. 
Por otra parte, siguiendo a Rawls, Nagel subraya que la teoría moral normativa es independiente respecto a la metaética, y que «un cierto desacuerdo radical sobre el fundamento de la ética es compatible con un acuerdo sustancial sobre cuáles sean los factores importantes en la vida real» ${ }^{61}$. También aquí, donde está vigente un completo desacuerdo en materia metaética, se puede convenir sobre cuáles sean los valores morales sustanciales dignos de ser perseguidos. Y es este último tipo de acuerdo el que a fin de cuentas destaca verdaderamente en la solución de los conflictos morales. En el discurso moral, concentrarse sobre cuestiones de metaéticas (entendidas estas en sentido lato como cuestiones también sobre el fundamento justificativo de los valores propuestos) puede ser alguna vez desviante e inoportuno, en cuanto puede dar origen a contrastes tales que obscurezcan el acuerdo de fondo (sobre cuestiones morales sustanciales) existentes entre las partes.

Nagel se detiene también sobre la cuestión de la justicia social. El filósofo americano reconoce la injusticia tanto de las desigualdades que derivan de la pertenencia a diferentes clases sociales cuanto aquellas que tienen su origen en la diferente capacidad y talento de los diversos seres humanos.

Nagel distingue tres concepciones de igualdad moral: (i) el utilitarismo, (ii) la teoría de los derechos, (iii) el igualitarismo ${ }^{62}$. La primera es una clase de aplicación de la regla de mayoría, ya que una acción es juzgada con referencia a la cantidad de utilidad que puede promover, y es preferida la acción que comporta una mayor cantidad de utilidad; «Se debe hacer lo que tienda a promover los resultados que parecen mejores desde el punto de vista que combina todos los intereses individuales. La igualdad moral del utilitarismo consiste en hacer que los intereses de cada persona contribuyan en el mismo modo a determinar aquello que sumándolos sería el total mejor» ${ }^{63}$.

Permanece el problema de la unidad de medida de la utilidad, excepto que no se conecte esta a la subjetiva expresión de la preferencia individual. Esta última solución sin embargo puede resultar insatisfactoria, como es subrayado por ejemplo por Thomas Scanlon ${ }^{64}$.

Para la «teoría de los derechos» la igualdad consiste en la igual pretensión de los individuos de no tolerar interferencias en su esfera personal por parte de terceros. «Cada persona debe ser

${ }^{61}$ Th. Nagel, op. ult. cit., p. 139.

${ }^{62}$ Vid. Th. Nagel: Mortal Questions, cit., capítulo octavo.

${ }^{63}$ Th. Nagel: Mortal Questions. Cit. por trad. it., p. 113.

${ }^{64}$ «Vid. Th. Scallon: Preference and Urgency, in «Journal of Philosophy», vol. 57, 1975, pp. 659-660. 
tratada igual que cualquier otra en ciertos aspectos definidos ${ }^{65}$. El concepto de derecho subjetivo sería así intrínsecamente igualitario, ya que presupone que todos lo posean. Para Nagel, sin embargo, se puede hablar con propiedad de derechos sólo en lo que concierne a pretensiones dirigidas a conductas omisivas, a comportamientos negativos, a la abstención de ciertas acciones: el concepto de derecho subjetivo expresa así «una pretensión que da a quien la posee una especie de poder de veto ${ }^{66}$.

La ética de los derechos actúa directamente sobre cada una de las acciones de los individuos y no sobre un cierto grupo de estas. Ella no impone -señala Nagel- la minimización de la violación de los derechos, sino la abstención de cualquier violación de derechos. Así, según la ética de los derechos, una conducta sobre la cual un derecho subjetivo me concede un poder de veto no debe ser ejecutada, aunque tal conducta que viola mi derecho pudiese reducir el número y la fuerza de sucesivas violaciones de derechos. En tal sentido esta ética se presenta como absoluta. Según Nagel la ética de los derechos es particularmente relevante por la que concierne a las conductas humanas en tiempo de guerra. La ética de los derechos sería en este caso más plausible que cualquier forma de utilitarismo. Mientras que este último puede justificar, por ejemplo, la tortura del enemigo, en el caso de que las informaciones sonsacadas a este sirvan para impedir -supongamosel aniquilamiento de un regimiento de miles de soldados; para la ética de los derechos la tortura es absolutamente ilícita, de modo que su prohibición no admite excepción alguna. «Una ética de ese tipo no impone minimizar la violación de los derechos. Esto significa considerarlos simplemente como males particularmente graves en la valoración de los resultados. Sin embargo los derechos limitan directamente la acción: se prohíbe a cada individuo violar directamente los derechos de los otros, aun si él pudiera indirectamente reducir el número conjunto de violaciones de derechos violando algunos él mismo» ${ }^{67}$.

La tercera concepción de igualdad moral individuada por Nagel es llamada por él simplemente «igualitarismo». Esta se parece al utilitarismo, en cuanto que -a diferencia de la ética de los- se aplica a la valoración no de las acciones en sí consideradas, sino a los resultados de éstas. Además, diversamente de cuanto sucede en la ética de los derechos, para el «igualitarismo» el individuo es titular de pretensiones no sólo respecto a

\footnotetext{
${ }^{65}$ Th. Nagel, op. ult. cit., p. 113.

${ }^{66}$ Ibid., p. 114.

${ }^{67}$ Ibidem.
} 
comportamientos omisivos, sino también a acciones positivas. Sin embargo, a diferencia del utilitarismo, el «igualitarismo» «no combina todos los puntos de vista con el método de las mayorías ${ }^{68}$, sino que establece una escala de urgencia y prioridad entre las distintas preferencias individuales, de modo que la valoración final no se basa sobre la cantidad o sobre el número de estas, sino sobre su calidad. «La característica esencial -escribe Nagelde un sistema de prioridad igualitario es que considera la mejora del bienestar del que está peor como más urgente que la mejora del bienestar del que está mejor» ${ }^{69}$. Aquí el problema es el fundamento del criterio de prioridad entre las diversas preferencias.

Nagel no elige, entre las tres concepciones de igualdad que acabamos de discutir (i) «utilitarismo», (ii) «ética de los derechos», y (iii) «igualitarismo». A su entender, es necesario que todas se combinen en la valoración de las elecciones sociales, pues el estudioso americano niega que el utilitarismo y la ética de los derechos representen aisladamente la solución a los problemas de la justicia.

Nagel objeta al utilitarismo que una solución justa debe ser, en vía de principio, aceptable por todo individuo. «Este ideal de aceptabilidad individual está en oposición fundamental con el ideal acumulativo, que construye un punto de vista moral particular combinando los de los individuos en un único punto de vista conjunto distinto del de todos ellos. Esto es obtenido por el utilitarismo sumándolos» ${ }^{70}$.

A la ética de los derechos Nagel le objeta que deja fuera del ámbito de lo justo gran parte del espacio de vida de los seres humanos. Además, esta ética dejaría fuera de la consideración moral las consecuencias de las acciones en cuestión, de un modo tan radical que resultaría inaceptable: «un punto de vista moral -escribe el filósofo americano- que no da fuerza al valor de los resultados conjuntos no puede ser correcto» ${ }^{71}$.

Al igualitarismo, finalmente, Nagel le objeta que descuida demasiado la relevancia que el número, la cantidad, puede asumir bajo ciertas condiciones». Mi opinión -escribees que ninguna teoría plausible puede evitar completamente la relevancia de los números» ${ }^{72}$.

\footnotetext{
${ }^{68}$ Ibid., p. 116.

${ }^{69}$ Ibidem.

${ }^{70}$ lbid., p. 122.

${ }^{71}$ lbid., p. 121.

${ }^{72}$ lbid., p. 124.
} 
Allí donde se plantea el problema de la eliminación de la desigualdad social Nagel ve sólo dos posibles regímenes económicos alternativos: o el régimen concurrencial de mercado o bien el centralizado de economía estatalizada; en otros términos o capitalismo o colectivismo burocrático. Nagel tomó partido por la economía de mercado, atemperada sin embargo por mecanismos de redistribución de la renta (de un lado por la vía de la imposición fiscal y por otro lado por la de los servicios sociales) que tienda a reequilibrar las diferencias creadas por el mercado. Por lo que concierne a la justicia social a nivel mundial, y la desigualdad entre los países ricos y los pobres, la única posibilidad dada por Nagel es la del gobierno mundial, el cual operaría como un enorme omnicomprensivo Welfare State.

Frente a un planteamiento semejante nos podemos cuestionar el siguiente interrogante: ¿Por qué un pensamiento reflexivo que se interroga sobre todo, incluso sobre sus propios fundamentos, debería detenerse en el umbral de las instituciones económicas? ¿Por qué deberíamos aceptar los modelos existentes como los únicos posibles? Nagel paga aquí, tal vez, el pecado mayor de la filosofía analítica, sobre la cual hace algunos años se ha dirigido el dedo acusador de Alasdair MacIntyre: la falta de perspectiva histórica acerca de los problemas tratados» ${ }^{73}$. El mercado no es efectivamente una institución «de razón» (en el sentido de su connaturalización con la racionalidad humana), tanto es así que es difícilmente encontrable antes de mil cuatrocientos. ¿Y entonces por qué no lo podemos someter también a la crítica de un «pensamiento débil» (cual es en sustancia el auspiciado por Nagel) privado de certeza, y en consecuencia lleno de dudas incluso respecto al status quo?

\section{El significado de la vida}

What Does It All Mean? concluye con una serie de consideraciones sobre la muerte y sobre el significado de la vida, temas ya afrontados tanto en Mortal Questions como en The View from

${ }^{73}$ Cfr. A. Macintyre: After Virtue. A Study in Moral Theory, II ed., Duckworth, London 1990, p. 23 ss. [Hay trad. cast. de A. Valcárcel, Tras de la virtud, Barcelona, Crítica 1987]. La reflexividad de la filosofia no implica necesariamente la ausencia o el rechazo de cada perspectiva histórica. Como escribe Castoradis, «la philosophie est una activité réflexice que se deplaie à la fois librement et sous contrainte de son propre passé. La philosophie n'est pas acumulative mais elle est profondément historique» (C. Castoriadis: La "fin de la philosophie”, en ID., Le monde morcelé, cit., p. 232. 
Nowhere. Temas semejantes, en efecto, no eran admitidos por el neopositivismo y por la filosofía analítica más rigurosa entre los objetos del análisis filosófico. No obstante la obra de Nagel, violando el precepto de Wittgenstein en el Tractatus, no permanece silenciosa sobre ellos.

Sobre el problema de la muerte es conocidísima la máxima epicúrea según la cual no tenemos razón de temer a la muerte, ya que apenas existe ella no existimos nosotros, y cuando nosotros existimos ella no está presente todavía. "Aut fuit, aut veniet, nihil est praesentis in illa»-escribe sobre la muerte La Boétie a Montaigne ${ }^{74}$.

Nagel a este propósito subraya que el miedo a la muerte no es tanto el miedo a un dolor en particular, a un encuentro, a una visión, sino más bien reside todo en el miedo a la ausencia. Es justamente el hecho de no existir más lo que nos asusta. «La mayor parte de la gente -escribe- quiere que dure más aquello de que gozan en la vida, pero para algunos la perspectiva de la no existencia es en sí misma espantosa, en un modo que no es adecuadamente explicado por cuanto se ha dicho hasta aquí. El pensamiento de que el mundo irá adelante sin ti, es muy difícil de aceptar» ${ }^{75}$. El miedo a la muerte es algo más que el dolor por el fin de la vida.

Lucrecio justifica la opinión según la cual el miedo a la muerte sería irracional e inmotivado argumentado, nadie puede estar asustado por la conciencia de la eternidad en la cual no ha vivido antes de nacer. ¿Por qué entonces se debe estar asustado frente a la eternidad que se proyecta después de nuestra muerte? Nagel objeta que los dos períodos no son especulares ni intercambiables, y que sólo el segundo -la eternidad después de la muerte- resulta una «privación» respecto a algo que habríamos podido tener. Sólo la eternidad después de la muerte se nos presenta como una sustracción de bienes. «Es verdad -escribe Nagel que el tiempo que precede al nacimiento de un hombre, y el tiempo que sigue a su muerte, son tiempos en los cuales no existe. Pero el tiempo después de la muerte es un tiempo del cual su muerte le priva» ${ }^{76}$.

${ }^{74}$ Vid. M. de Montaigne: Essais, livre 1, chapitre 14 (ed. Flammarion, vol. 1. París 1969, p. 96).

${ }^{75}$ Th. Nagel: What Does It All Mean? Cit. por trad. it. (levemente modificada), p. 109. Cursiva en el texto.

${ }^{76}$ Th. Nagel: Mortal Questions. Cit. por trad. it. p. 15. Una reformulación del argumento de Lucrecio es aquella de Montaigne: «Comme nostre naissance nous apporta la naissance de toutes choses, aussi fera la mort de toutes choses, nostre mort. Parquoy c'est pareille folie de pleuer de ce que d'icy á cent ans nous 
Pero ¿cuál es el significado de la vida? Esta es una de aquellas «cuestiones mortales» que al parecer de Nagel alimentan el trabajo del filósofo y entran de pleno derecho en el ámbito de la filosofía. Como se ve, no podría haber nada más distante al pensamiento del filósofo americano que la concepción que concibe la filosofía como metadiscurso o metaciencia. Nagel es cáustico hacia los filósofos «sick of the subject and glad to be rid of its problems» ${ }^{77}$, y hacia «a persistent temptation to turn philosophy into something less difficult and more shallow than it is» ${ }^{78}$.

El problema del significado de la vida y de aquello que en general los seres humanos hacemos o producimos se revela en el hecho de que por más esfuerzos que se puedan dedicar a una obra, y por más que sea bella, interesante, perfecta, está, no obstante, destinada un día a desaparecer, así como desaparecerán la tierra y el sol. Sub specie aeternitatis todo es vano, no sólo el estudio que yo estoy bosquejando, sino también el libro mismo de Nagel y la Ética Nicomaquea de Aristóteles. Ese es el destino no sólo del papel impreso o escrito. También las obras de albañilería y de acero son portadoras del virus de la caducidad, ordenadores, satélites, y rascacielos incluidos.

La conclusión de Nagel es entonces la siguiente. «Si existe algún significado en lo que hacemos debemos encontrarlo en nuestras vidas $\rangle^{79}$. Nuestras vidas tienen sentido sólo desde dentro, desde un punto de vista «interno» (que obviamente no tiene nada que ver con el teorizado por H.L.A. Hart $\left.{ }^{80}\right)$. «El problema es -continúa Nagel- que si bien existen justificaciones y explicaciones para la mayoría de las cosas, grandes y pequeñas, que hacemos en la vida, ninguna de estas explicaciones explica la esencia de tu vida como un todo- el todo del que todas estas actividades, éxitos y fracasos, forman parte. Si pensamos en el quehacer conjunto no parece existir en él ningún significado. Mirándolo desde el exterior no tendría importancia alguna si tú no hubieras existido jamás. Y después de que tú salgas de la

ne vivrons pas, que de pleuer de ce que nou ne vivions pas il y a cent ans». (Essais, livre I, chapitre XX (ed. Flammarion, vol 1, Paris 1969, p. 137)).

${ }^{77}$ Th. Nagel: The View from Nowhere, Oxford University Press, New York 1986, p. 11.

${ }^{78}$ Ibid., p. 12.

${ }^{79}$ Th. Nagel: What Does It All Mean? Cit. por trad. it., p. 113.

${ }^{80}$ Vid. H.L.A. Hart: The Concept of Law, Clarendon, Oxford 1961, pp. 55-56, pp. 86-88. [Hay trad. cast. de R. Carrio Genaro, El concepto de derecho, Buenos Aires, Abeledo Perrot 1968. N. del T.]. 
existencia no importará que tú hayas existido» ${ }^{81}$. Podría decirse tal vez que para el que termina de vivir es como si no hubiera vivido nunca.

El sentido de la vida se ha hecho residir alguna vez en algo que «transciende» al singular individuo, o mejor en algo que es como un «todo» respecto a la «parte» representada por el individuo, en un movimiento político, en la vida futura de los propios hijos, en la vida eterna en contacto con Dios. No obstante tampoco estos «todos» se escapan de la pregunta respecto a su «sentido». ¿Cómo se justifican? ¿No será necesario también para ellos un «todo» más comprensivo todavía, del cual deducir su «sentido»?

La respuesta más fuerte a la cuestión sobre el sentido de la vida la ofrece la fe en la existencia de lo divino. Nagel sin embargo no está satisfecho. «La idea de Dios parece ser la idea de algo que puede explicar todo lo demás, sin deber ser explicada en sí misma. Pero es muy difícil comprender cómo podría ser una cosa de este género. Si planteamos la cuestión «¿Por qué el mundo es así? y se nos ofrece una respuesta religiosa, cómo se puede impedir preguntarnos entonces “¿Y por qué es verdad?”. ¿Qué tipo de respuesta haría cesar todos nuestros "porqués una vez por todas"? ¿Y si se detienen allí por qué no podrían haberse detenido antes?» ${ }^{82}$.

Así llegamos a la afirmación del absurdo de la condición humana, una conclusión que alcanza a la obra de Camus ${ }^{83}$. Si se acepta la idea de Dios -argumenta Nagel-, pero no se está en situación de explicar tal idea, la aceptación de ella es incomprensible y como tal absurda. Si en cambio no se acepta la hipótesis de la divinidad como clave del mundo, nuestra ínfima, frágil, limitadísima existencia se tiñe una vez más con los colores del absurdo.

La lección a extraer de todo ello -según Nagel- es la de no tomarse demasiado en serio, entender que contamos sobre todo «desde el interior». Muchos esfuerzos, que hoy emprendemos, muchas ambiciones que hoy nos mueven, aparecerán así como lo que son en realidad: vanidad y nada más ${ }^{84}$. «Si la vida no es real, la vida no es una garantía, y la muerte es su finalidad, tal vez es ridículo tomarnos tan seriamente. Por otra parte, si no podemos

${ }^{81}$ Ibid., p. 114

${ }^{82}$ Ibid., p. 117.

${ }^{83}$ Cfr. J. Gordon: Nagel or Camus on the Absurd, en «Philosophy and Phenomenological Research», vol. 45, 1984, p. 15 ss.

${ }^{84}$ Esto por otra parte puede constituir un alivio. Como escribe Colin McGinn, «too much meanig in life can be a burden; insignificance can lighten the heart» (C. McGinn, recensión die Th. Nagel: The View from Nowhere, en «Mind», vol. 96, 1987, p. 272). 
evitar tomarnos en serio, tal vez debamos resignarnos a ser ridículos. La vida puede ser no sólo insensata sino absurda» ${ }^{85}$.

Hay en el planteamiento de Nagel frente al absurdo una notable diversidad de acento respecto al tono usado por Camus. Mientras que Camus sostiene que la única conducta que nos permite hacer frente al absurdo del mundo y al de nuestra condición es la rebelión contra estos y en consecuencia el titanismo, de modo que «il faut imaginer Sisyphe hereux», ya que «la lutte elle-même suffit à remplir un coeur d'homme» ${ }^{86}$, el planteamiento de Nagel es bastante menos romántico y dramático. El titinismo para Nagel significaría tomarse nuevamente demasiado en serio, y de algún modo dramatizar la percepción del absurdo. Se reafirma así el no absurdo de algo en el mundo, es decir de lo absurdo por tanto, a fin de cuentas, se contradeciría su asunción. Si todo es irrelevante también el hecho que sea así lo es. Si todo es insensato, también nuestra lucha contra ello no tiene sentido. La conclusión es la ironía y no el esfuerzo titánico: «Si sub specie aeternitatis no existe razón para creer que cualquier cosa tenga importancia, entonces tampoco esto tiene importancia, y podemos acercarnos a nuestra vida absurda con ironía en vez de con heroísmo o desesperación ${ }^{87}$.

\section{La función de la filosofía}

El punto de llegada de Tom Nagel es -corno ya se ha hecho referencia- una especie de «pensamiento débil», una filosofía privada de certeza absoluta, que se detiene en la orilla del relativismo y del escepticismo, y no rechaza los instrumentos racionalistas y analíticos. Al «pensamiento débil» el estudioso americano llega a través de la vía de la filosofía analítica, no a lo largo de los caminos de la «crítica de la razón» batidos por los post-marxistas, post-nietzschianos y post-heideggerianos.

La filosofía analítica de Nagel es, por motivos diversos, sui generis. Ante todo no opera aquel linguistic turn que parece caracterizar la filosofía analítica en sentido estricto ${ }^{88}$. Nagel se

${ }^{85}$ Th. Nagel, op. ult. cit., p. 119.

${ }^{86}$ A. Camus: Le mythe de Sisyphe, Gallimard, Paris 1978, p. 166. [Hay trad. cast. El mito de Sísifo, O,C. tomo II, México, Aguilar 1968 (3º].

${ }^{87}$ Th. Nagel: Mortal Questions. Cit. por trad. it., p. 29. Sobre la ironía como virtud filosófica, cfr. M. Merleau-Ponty, Eloge de la philosophie, Gallimard, Paris 1953.

${ }^{88} \mathrm{Cfr}$. lo escrito por M. Dummett, Alle origini della filosofia analitica, trad. it. de E. Picardi, Il Mulino, Bolonga 1990, p. 11: «Lo que distingue a la filosofía 
mantiene adherido a una Bewusstseinsphilosophie; su punto de partida es el sujeto o la consciencia de éste, y no se pasa por esto a la Sprachphilosophie ${ }^{89}$, esto es, a una filosofía que se mueve exclusivamente por el análisis de las expresiones lingüísticas y asume -como es explícito por ejemplo en Wittgenstein- nítidos contornos antisubjetivistas. La filosofía de Nagel es más bien una fenomenología de la experiencia subjetiva conducida con instrumentos analíticos, sin el uso de fórmulas técnicas, agarrada al sentido común. «El sentido común -escribe el estudioso americano- no tiene la última palabra en ética o en cualquier otro ámbito, pero tiene [...] la primera palabra; debería ser examinado antes de ser descartado» ${ }^{90}$.

La no adhesión a la Sprachphilosophie explica por ejemplo el extremismo racionalita (o mejor dicho, «reflexivista») de Nagel, para el cual es siempre posible distanciarse de la propia «historia», del propio rol, de la propia comunidad lingüística, de los propios valores, atestiguarlos estos críticamente, a partir de un «ningún lugar» que es el lugar propio del filósofo. Nagel es por esto un crítico decidido de cada forma de historicismo. «Una cosa -escribe- es reconocer las limitaciones que inevitablemente derivan de ocupar una posición particular en la historia de una cultura; otra es convertirla en su inverso, abrazando un historicismo que dice que no hay verdad si no es interna a una particular perspectiva histórica» ${ }^{91}$.

Como ya se ha tenido ocasión de señalar, Nagel se distancia también de la tradición neoempirista que asigna a la filosofía un terreno bastante limitado y la convierte en sólo un metalenguaje, metaciencia ${ }^{92}$. Los problemas filosóficos - para el estudioso

analítica (...) es el convencimiento en primer lugar de que una explicación filosófica del pensamiento puede conseguirse a través una explicación filosófica del lenguaje, y en segundo lugar, de que una explicación comprensiva puede conseguirse sólo de esta manera.

${ }^{89}$ «Para la diferencia entre Bewussteseinsphilosophie e Sprachphilosophie, cfr. J. Habermas: Nachmetaphysisches Denken. Philosophische Anfsätze. Suhrkamp, Frankfurt am Main 1988, p. 15.

${ }^{90}$ Th. Nagel: The View from Nowhere. Cit. por trad. it., p. 205.

${ }^{91}$ Ibid., p. 12.

${ }^{92}$ A esta posición se podría añadir lo que Montaigne escribe a propósito de esos filósofos que, oponiéndose al triunfalismo de cuantos adscriben cada saber a la filosofía, acaban por negar a esta cualquier competencia cognoscitiva: "Ainsin est-il advenu en l'escole de la philosophie: la fierté de ceux qui attribuoyent à l'esprit humain la capacité de toutes choses causa en d'autres, par despit et emulation, cette opinion qu'il n'est capable d'aucune chose» (M. de Montaigne: Essais, livre 3, chapitre 11 [ed. L. vol. 3, Paris, Flammarion 1969, p. 247]). 
americano- no derivan del mal uso del lenguaje. "Ciertas formas de perplejidad -escribepor ejemplo la libertad, el conocimiento y el significado de la vida me parecen incorporar más perspicacia que cualquiera de las presuntas soluciones a estos problemas. La perplejidad no deriva del error en el funcionamiento del lenguaje y de la reflexión, y no hay esperanza alguna de una pureza kantiana o wittgensteiniana, alcanzable si evitamos pasos falsos que nos surgen en el empleo de la razón o del lenguaje» ${ }^{93}$.

Para Nagel la filosofía es un lenguaje de primer grado, se interroga sobre el mundo y sobre la existencia según modalidades que son extrañas a la ciencia. La diferencia entre ciencia y filosofía pasa aquí no tanto a lo largo de sus respectivos objetos de investigación sino más bien del diverso método intelectual que la filosofía y la ciencia utilizan.

La «contrafacticidad» de la argumentación es útil en algunos pasajes del pensamiento científico, pero debe finalmente ceder el paso a argumentos fundados sobre la «facticidad», sobre la observación. En la ciencia, a fin de cuentas, contra factum non valet argumentum. En filosofía, al contrario, la «contrafacticidad» de la argumentación es constante y irrenunciable, también allí donde no se quiere aflojar el agarre del sentido común. Los problemas típicos de la filosofía son questiones iuris no questionis facti.

Mientras la ciencia es investigación que se mueve desde un lugar concreto y tiene una perspectiva precisa, la filosofía es -dice Nagel- «the view from nowhere», una mirada desde ningún lugar. Verdaderamente, esto es una pretensión absurda, ya que -como nos recuerdan entre otros MacIntyre y Rorty ${ }^{94}$ - ningún ser humano puede hacerse extraño ajeno completamente del lugar en el cual se encuentra, de la «historia», de la tradición de la que parte. La filosofía pretende que el hombre se alce él mismo sobre la tierra, tirándose por la coleta a la manera del barón de Münchausen. Todavía - replica Nagel- la filosofía vive de esta absurda pretensión, y encuentra su fundamento en la capacidad (limitada cuanto se quiera) del hombre de asumir un punto de vista «objetivo».

${ }^{93}$ Th. Nagel, op. ult. cit., p. 4.

${ }_{94}$ «So rationality itself -escribe Macintyre-, whether theoretical of practical, is a concept with a history: indeed, since there are a diversity of traditions of enquiry, with histories, there are, so it will turn out, rationalities rather the rationality, just as it will turn out that there are justices rather tan justice» (A. MacIntyre: Whose Justice? Which Rationality?, Duckworth, London 1988, p. 9). 
Así, aunque «débil» (en cuanto relativista), la filosofía propuesta por el estudioso americano tiene «fuerte» el sentido del propio específico rol. Nagel está bien alejado de las tentaciones imperialistas de la filosofía idealista, para la cual el saber es esencialmente filosófico, y no existen ámbitos de conocimiento en los cuales no tenga la última palabra. Está sin embargo alejado de aquellas posiciones para las cuales la filosofía es una clase de pensamiento precientífico, que no tiene razón de ser una vez que la ciencia sea desarrollada adecuadamente. «La filosofía -escribe Nagel- está también contagiada por una tendencia más amplia de la vida intelectual contemporánea: el cientifismo. El cientifismo es en realidad una forma especial de idealismo, en cuanto asigna a un sólo tipo de comprensión humana la supervisión del universo y de cuanto puede ser dicho sobre ello. En su forma más miope, asume que todo lo que existe debe ser comprensible a través del empleo de las teorías científicas que hayamos desarrollado hasta ahora -la física y la biología evolucionista son los paradigmas corrientes- como si el tiempo presente no fuese simplemente más que otro en la serie» ${ }^{95}$. La conclusión es entonces que «se ha perdido demasiado tiempo a causa de la asunción según la cual métodos ya existentes resolverían problemas a los cuales no están destinados $\gg{ }^{96}$.

Filosofía es -en la perspectiva de Nagel- un pensamiento radicalmente reflexivo, que sirve para atribuir un status de discusión y de contingencia a lo que de otro modo se nos presenta con los atributos de lo apodíctico y de la necesidad más implacable. «Darse una razón» de lo que se ve, se cree o se hace, esto es para Nagel la tarea nunca cumplida del filósofo, un esfuerzo de Sísifo. No hay sin embargo en esta imagen ningún pathos elitista. La filosofía para Tom Nagel no debe practicarse necesariamente en las Universidades, en las academias; también puede hacerse en la calle. Filosofía no es un Glasperlenspiel para iniciados, sino una actividad que puede ser de cada hombre.

Así Nagel no suscribe -creo- la concepción que Habermas ha formulado recientemente respecto a los fines de la filosofía moral. Esta - para el filósofo alemán- puede ofrecer sólo un procedimiento, una estructura formal, dentro de la cual corresponde a los sujetos particulares desarrollar teorías normativas sustanciales. Se trata paradójicamente de una reedición de la concepción según la cual la ética filosófica puede ser sólo metaética. «El filósofo moral -escribe Habermas- no dispone

${ }^{95}$ Th. Nagel. op. ult. cit., p. 11.

${ }^{96}$ Ibidem. 
de un acceso privilegiado a las verdades morales $\gg{ }^{97}$. Y de esta afirmación extrae la conclusión de que la filosofía moral debe detenerse frente a las cuestiones concretas» ${ }^{98}$.

Nagel, que comparte las afirmaciones según las cuales el filósofo no dispone de un criterio seguro y privilegiado para la decisión de las controversias morales, deduce de esta convicción una conclusión opuesta a aquella de Habermas. El filósofo moral, que para Nagel (a diferencia de Habermas) no es sólo el «experto» o el académico, se interroga ante todo sobre «lo que es justo hacer». Es decir, Nagel entiende la filosofía moral como actividad reflexiva que se ejercita eminentemente respecto a cuestiones concretas, ya que el interrogante sobre «lo que es justo hacer» o «lo que debo hacer», sólo tiene sentido si se refiere a una situación o a una conducta concreta. La filosofía moral no es entonces necesariamente privilegio de pocos, del «clérigo», sino que puede ser práctica difusa, común a todos aquellos que se interrogan sobre la «justicia» y el «deber ser» de las conductas humanası ${ }^{99}$.

(Traducción de Cristina García Pascual, revisada por el autor)

${ }^{97}$ J. Habermas: Moralität und Sittlichkeit. Treffen Hegels Einwäande gegen Kant auch auf die Diskursethik zu?, in «Revue internationale de philosophie» vol. 42, 1988, p. 339. Traducción del propio autor.

${ }^{98}$ Vid. por ejemplo J. Habermas: Die nachholende Revolution, Suhrkamp, Frankfurt am Main 1990, p. 144: «IOch halte es für die Aufgabe der Philosophie, die Bedingungen zu klären, unter denen sowohl moralische wie ethische Fragen von den Beteiligten selbst rational beantwortet werden konen».

${ }^{99}$ El carácter democrático de la filosofía es reivindicado con fuerza por Cornelius Castoriadis. Vid. C. Castoriadis: Pouvoir, politique, autonomie, ahora en ID., Le monde morcelé, cit., p. 127. 